\title{
Metastatic multiple myeloma with hyperamylasaemia and hyperlipasaemia
}

\author{
Satheesh Nair, Pavan Sachan, Hilary Hertan, C S Pitchumoni
}

Our Lady of Mercy of University Medical Center, Bronx, NY 10466, USA

P Sachan

H Hertan

C S Pitchumoni

Correspondence to

Dr CS Pitchumoni MD

FACG, Chief, Division of

Gastroenterology, Our Lady of Mercy University Medica Center, 600 East 233rd

Street, Bronx, NY 10466, USA

\begin{abstract}
A 47-year-old non-alcoholic African-American woman was diagnosed to have multiple myeloma in December 1995. She received several cycles of chemotherapy with melphalan and prednisone. Initial days of chemotherapy were punctuated by recurrent hospital admissions for vomiting and abdominal discomfort, presumably due to chemotherapy. Serum amylase and lipase levels remained within normal limits during these admissions. Eighteen months after the initial diagnosis, she developed shortness of breath and left-sided chest pain. Serum lipase and amylase levels were normal. Computed tomography (CT) of the chest revealed a left intrathoracic pleural mass and bilateral effusions. Palliative radiotherapy was given to the left hemithorax, in addition to another cycle of chemotherapy.

Six weeks later, the patient developed abdominal distension and vomiting. Physical examination revealed a toxic-looking woman with moderate ascites. Laboratory values on the day of admission were as follows: leucocytes $6.7 \times 10^{9} / 1$, serum calcium $8.8 \mathrm{mg} / \mathrm{dl}$ (normal $8.5-10.5$ ) serum lipase $114 \mathrm{IU} / 1$ (normal 4-24) and a serum amylase of $2306 \mathrm{IU} / 1$ (normal 44-128). A CT scan of the abdomen showed ascites with a large intra-abdominal mass on the left side. The pancreas was normal. Magnetic resonance imaging of the abdomen and pelvis supported CT scan findings. Abdominal sonogram was negative for gallstones. Ascitic fluid cytology revealed malignant plasma cells. Ascitic fluid amylase was $8500 \mathrm{IU} / 1$.
\end{abstract}

\section{Questions}

1 What are the possible explanations of elevated amylase in a patient with multiple myeloma?

2 What additional test(s) would be useful?

Accepted 10 March 1998

3 What is the probable cause of elevated serum lipase in this patient? 


\section{Answers}

QUESTION 1

Acute pancreatitis should be the first consideration in such a patient, as acute pancreatitis secondary to hypercalcaemia is known to complicate the course of multiple myeloma. ${ }^{1}$ However, in our patient, none of the imaging studies showed any evidence of pancreatitis Although a normal CT scan need not necessarily rule out acute pancreatitis, two other considerations are important:

- Macroamylasaemia. In a healthy individual, the serum amylase is the net balance between amylase production from the pancreas (P-isoamylase: $40 \%$ ) and salivary gland (S-isoamylase $60 \%$ ) and clearance by kidneys or reticuloendothelial system. ${ }^{2}$ In certain individuals the amylase binds to proteins or immunoglobulins so that high molecular weight amylase is not cleared by kidneys, resulting in elevated serum amylase. In patients with multiple myeloma with elevated circulating immunoglobulins, macroamylase should be considered as a cause of hyperamylasaemia.

- Salivary hyperamylasaemia. Structural alteration in chromosome 1 where the salivary amylase gene is located, have been observed in myeloma cells. ${ }^{34}$ Such alterations lead to uncontrolled production of amylase by these malignant cells, leading to elevated serum amylase. This is extremely rare and only a handful of cases have been published. However, for reasons not well elucidated, such ectopic amylase production has only been reported in cases of metastatic multiple myeloma. Ectopic salivary amylase production is well recognised from benign ovarian cysts and papillary cystadenocarcinomas and rarely in carcinoma of lung, colon and thymomas. ${ }^{2}$ There is only one case report of ectopic production of $\mathrm{P}$-isoamylase in a patient with breast cancer. ${ }^{5}$ These tumourderived amylase molecules may have a different amino acid composition from normal amylase

Table Causes of elevated isoamylases

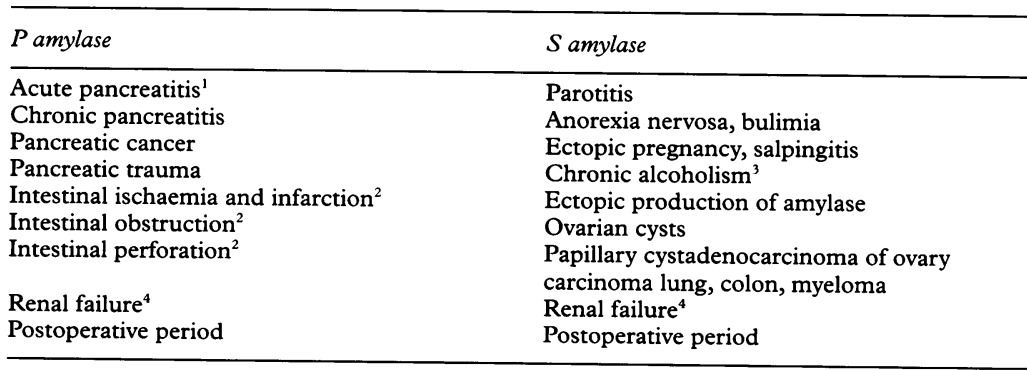

${ }^{1}$ Serum amylase can, rarely, be normal in acute pancreatitis (if there is massive pancreatic necrosis, delay in estimating serum amylase after the onset of symptoms, or if acute pancreatitis is secondary to hypertriglyceridaemia)

${ }^{2}$ Elevated serum amylase level is due to leakage of amylase from the bowel lumen into serum and the levels are rarely more than three times normal

${ }^{3} 10 \%$ of chronic alcoholics have elevated salivary amylase; these individuals are at risk of acute as well chronic pancreatitis

${ }^{4}$ Renal failure results in elevation of both P-and S-amylase. Serum lipase can also be elevated in renal failure (the elevations in amylase and lipase are seldom more than three times normal)
QUESTION 2

Urine amylase and isoamylase estimation, with either electrophoresis or chromatography, would be useful. Elevated urine amylase in a patient with hyperamylsaemia effectively rules out macroamylasaemia and suggests a P- or $\mathrm{S}$-isoamylase elevation. Likewise, a normal to low urine amylase in a patient with elevated serum amylase is indicative of macroamylasaemia, though rarely some salivary-type amylase can be cleared slowly, resulting a low urinary clearance similar to macroamylase. Apart from diagnosing macroamylasaemia, estimation of urine amylase or amylase creatinine clearance has no other clinical use. Twenty-four hour urine amylase in our patient was $17400 \mathrm{IU} / 1$ which excluded the possibility of macroamylasaemia as the cause of elevated serum amylase.

Isoenzyme estimation can determine the type of amylase (S or P) that is elevated. Electrophoresis can also detect macroamylase. In the patient described here the serum amylase was almost entirely composed of S-amylase (98\%) with a low P-isoenzyme. There was no macroamylase. It is most likely that the source of elevated amylase in our patient was ectopic production of S-amylase from the myeloma cells. It is interesting that, despite the presence of metastatic tumour, this patient did not have hyperamylasaemia on previous admissions. It is possible that the radiotherapy to the thoracic wall may have triggered the structural alteration in the tumour cells leading to salivary amylase production. ${ }^{6}$ The causes of elevated isoamylases are highlighted in the table.

\section{QUESTION 3}

The probable cause of elevated serum lipase in this patient is macrolipase. For all practical purposes, the pancreas is the only source of serum lipase and hence elevated serum lipase is considered to be a more specific marker for pancreatitis (gastric lipase contributes minimally to serum lipase). Elevated serum lipase in the absence of pancreatitis is seen in renal insufficiency and in surgical conditions of the abdomen, such as bowel obstruction and perforation, and ischaemia. However, there are two welldocumented reports of elevated serum lipase in patients with high immunoglobulins as a result of immunoglobulin-lipase complex formation. ${ }^{78}$ Lipase levels in one of these patients returned to normal after correction of hyperimmunoglobulinaemia. It is likely that hyperlipasaemia in our patient was due to macrolipase formation, although we did not confirm it by chromatography. Our patient had a downhill course and developed fulminant sepsis and multi-organ failure and died within 2 years of diagnosis of multiple myeloma.

\section{Final diagnosis}

Macroamylasaemia, due to ectopic production of S-amylase from myeloma cells, and hyperlipasaemia, due to macrolipase formation, in a patient with multiple myeloma.

Keywords: multiple myeloma; hyperamylasaemia; hyperlipasaemia 
1 Ito T, Kimura T,Yamashita S, Abe Y, Haji M, Nawata $H$. Acute pancreatitis associated with hypercalcemia in patient with multiple myeloma. Pancreas 1992;6:396-8.

2 Bigelow CP, Strocchi A, Levitt MD. Where does serum amylase come from and where does it go? Gastroenterol Clin North Am 1990;19:793-810.

3 Lopez J, Ulibarrena C, Gonzalez Porque P, et al. Amylase producing Bence Jones multiple myeloma with pancreatitis producing Bence Jones multiple myeloma with

4 Fujii H, Yashinge H, Kanoh T,Urata Y. Amylase producing multiple myeloma. Arch Pathol Lab Med 1991;115:952-6.

5 Weitzel JN, Pooler PA, Mohammed R, et al. A unique case of breast carcinoma producing pancreatic type of amylase. Gastroenterology 1988;94:519-21.
6 Yamakawa T, Nagoshi H, Takahashi A. Acquired amylase production by radiotherapy in myeloma patient (Japanese). Rinso Ketsueki 1995;36:1175-81.

7 Bode C, Reiderer J, Brauner B, Bode JC. Macrolipasemia: a rare cause of persistently elevated serum lipase. $A m \mathcal{f}$ Gastroenterol 1990;85:412-6.

8 Stein W, Bohner J, Bahlinger M. Macrolipase: a new family of immunoglobulin linked enzymes. $f$ Clin Chem Clin Biochem 1987;25:837-43.

\title{
An enlarging abdominal mass
}

\author{
J Torkington, E R A Darrah, B O’Riordan
}

A 69-year-old farmer's wife presented with a 3-month history of a swelling over the lateral abdominal wall. Examination by her general practitioner suggested a diagnosis of lipoma but the lump grew rapidly over the ensuing weeks and the possibility of malignant change was raised. Therefore a CT scan was performed (figure).

\section{West Wales General \\ Hospital, Carmarthen, \\ Carmarthenshire \\ SA31 2AF, UK \\ Department of \\ Surgery \\ J Torkington \\ B O'Riordan \\ Department of \\ Radiology \\ E R A Darrah \\ Correspondence to \\ Mr J Torkington, \\ Department of General \\ Surgery, Ysbyty Gwynedd \\ Bangor, Gwynedd LL57 2 \\ PW, UK}

Accepted 10 March 1998

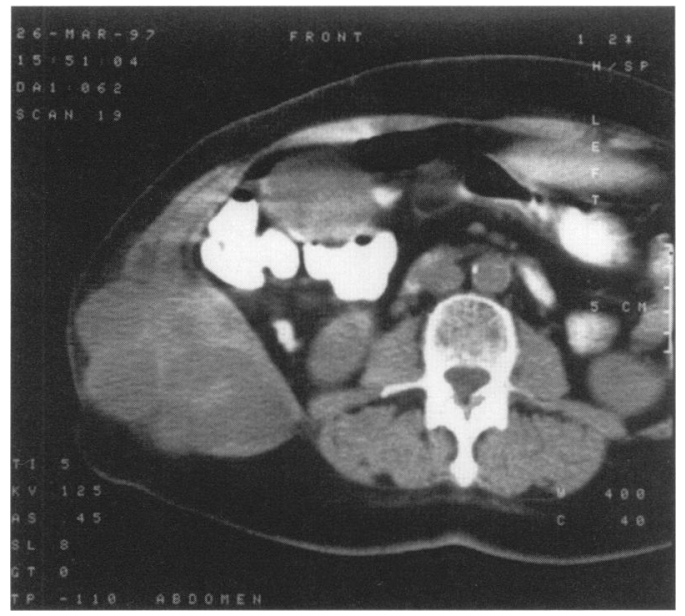

\section{Questions}

1 Describe the CT scan appearances.

2 Suggest the most likely diagnosis?

3 How does this condition normally present? 